\title{
Bir Konsol İstinat Duvarının Sismik Davranışına Yeraltı Su Seviyesindeki Değişimlerin Etkisinin İncelenmesi
}

\author{
Investigation of The Effect of Changes In Ground Water Level On The Seismic Behaviour of \\ A Cantilever Retaining Wall
}

\author{
Utku KÖKTAN*,a , Gökhan DEMİR ${ }^{\text {b }}$, M. Kerem ERTEK ${ }^{\mathrm{c}}$ \\ Ondokuz Mayıs Üniversitesi, Mühendislik Fakültesi, Inşaat Mühendisliği Bölümü, 55139, Samsun
}

• Geliș tarihi / Received: 26.02.2018 • Düzeltilerek geliş tarihi / Received in revised form: 24.10 .2018 • Kabul tarihi / Accepted: 31.10 .2018

\begin{abstract}
$\ddot{O} z$
Bu çalışmada bir istinat duvarının, zeminde farklı yeraltı su seviyeleri olması durumundaki dinamik davranışı zaman tanım alanında sonlu elemanlar yöntemi kullanılarak incelenmiştir. Zemin-yapı etkileşimini dikkate alarak gerçeğe daha yakın bir analiz yapabilmek amacıyla radyasyonel sönüm etkileri ve dalga yayılım etkileri dikkate alınmıştır. Bu amaçla duvardan belirli bir uzaklıkta zemin ortamı sonlandırılarak zemin ortamının sonundaki düzlemsel serbest yüzeylere viskoz sanal sınırlar uygulanmıştır. Zemin ile duvar arasındaki davranışı daha doğru modelleyebilmek için özel arayüzey elemanları kullanılmıştır. İstinat duvarına ait analizler MIDAS GTS NX sonlu elemanlar yazılımı ile bu yazılımın kütüphanesinde bulunan San Fernando Pacoima Dam depremine ait kayıt kullanılarak yapılmıştır. Zemin-yapı etkileşiminin çözümünde doğrudan çözüm yöntemi kullanılmıştır. Yapılan analizler neticesinde duvarın dinamik davranışı yerdeğiştirmeler ve gerilmeler cinsinden irdelenmiştir. Elde edilen sonuçlar neticesinde zemin-yap1 etkileşiminin istinat duvarının sismik davranışında çok büyük önem arz ettiği, yeraltı su seviyesindeki değişimlerin duvarın hareketini ve duvar üzerinde oluşan gerilmeleri önemli mertebelerde etkilediği görülmüştür.
\end{abstract}

Anahtar kelimeler: İstinat Duvarı, Yeraltı Suyu, Zemin-Yapı Etkileşimi

\begin{abstract}
In this study, dynamic behavior of a retaining wall for various ground water levels through soil is investigated in nonlinear time-history analysis using finite element method. In order to do a more realistic analysis taking soilstructure interaction into account, the effects of radiational damping and wave propagation were considered. For this purpose, soil medium has been capped off within a definite distance from the wall and virtual viscous boundaries were applied to the vertical free surfaces at both ends of the medium. Special interface elements were used to better model the behavior between soil and the wall. The analyses of the retaining wall subject to the study were carried out by using the finite element software MIDAS GTS NX and the record of San Fernando Pacoima Dam earthquake which exist in the library of the software. Direct solution method has been used in the analysis of soil-structure interaction. The dynamic behavior of the wall in the sequel of the analyses were probed in terms of stresses and displacements. In consequence of the results obtained, it has been seen that the soil-structure interaction has a great importance in the seismic behavior of the retaining wall and the variations in groundwater level significantly effect the movement of the wall and the stresses emanating on the wall.
\end{abstract}

Keywords: Retaining Wall, Ground Water, Soil-Structure Interaction

\footnotetext{
*a Utku KÖKTAN; utku.koktan@omu.edu.tr; Tel: (0362) 31219 19; orcid.org/0000-0002-8287-9586

${ }^{\mathrm{b}}$ orcid.org/0000-0002-3734-1496 $\quad{ }^{\mathrm{c}}$ orcid.org/0000-0002-8395-0321
} 


\section{Giriş}

İstinat duvarları, köprülerde kenar ayakları, rihtım duvarları, bir binanın bodrum katlarını oluşturan duvarlar, halatlı bölme duvarlar, kuşaklı kazılar, mekanik olarak stabilize edilmiş duvarlar vb. tiplerde, sismik açıdan aktif alanların her yerinde kullanılmaktadır. Bu yapılar; liman ve rıhtımların, taşıma sistemlerinin, nakil hatlarının ve diğer tesislerin genellikle ana unsurlarını oluşturmaktadır. Depremlerin, istinat duvarlarında genellikle kalıcı hasarlar meydana getirdiği açıkça bilinen bir gerçektir. Geçmişte meydana gelen depremlerin istinat duvarları üzerinde meydana getirdiği bu hasarlar zaman zaman ihmal edilebilir mertebelerde kalmış, zaman zamansa istinat duvarının yıkılması sonucu önemli fiziksel ve maddi kayıplara hatta can kayılarına sebebiyet vermiştir (Kramer, 1996).

Yüz ölçümünün büyük kısmı tektonik açıdan Afrika, Arap, Anadolu ve Avrasya levhalarının çarpışmaları sonucu ortaya çıkan karmaşık deformasyonların meydana getirdiği Akdeniz Deprem Kuşağı içerisinde bulunan ülkemizde meydana gelen sismik aktiviteler "Kuzey Anadolu Fay Zonu (KAFZ)", "Doğu Anadolu Fay Zonu (DAFZ)" ve "Batı Anadolu Gerilme Yapısı" olmak üzere üç ana oluşum tarafindan kontrol edilmektedir (Canbay vd., 2008). Bu sebeple yüzölçümünün $\% 42$ 'si 1 . derece, $\% 24$ 'ü 2 . derece, $\% 18$ 'i 3. derece, $\% 12$ 'si 4 . derece ve $\% 4$ 'ü ise 5 . derece deprem kuşağında yer alan ülkemizde, tüm mühendislik yapıları gibi istinat duvarlarının da depreme karşı dayanıklı olarak inşa edilmesi büyük önem arz etmektedir. (Özmen vd., 1997).

İstinat duvarlarıyla alakalı literatür incelendiğinde duvarın sismik davranışını belirlemek maksadıyla pek çok çalışma yapıldığı görülmektedir. $\mathrm{Bu}$ çalışmaları, 1) izin verilebilir yerdeğiştirmelere göre ortaya koyulmuş limit denge yaklaşımları, 2) duvarın rijit olduğu ve yer hareketinin oldukça düşük bir yoğunlukta olduğu kabulüyle dolgu zeminini lineer elastik veya viskoelastik tarzda tanımlayan yaklaşımlar ve 3) genellikle sonlu elemanlar metodu (SEM) kullanilarak zemin davranışını doğrusal elastik veya doğrusal olmayan elastoplastik şekilde tanımlayan yaklaşımlar olmak üzere üç ana grupta toplamak mümkündür (Veletsos ve Younan, 1994a).

Birinci kategorinin temelini Mononobe ve Okabe tarafindan ortaya konulan ve kendi isimleriyle anılan Mononobe-Okabe (M-O) yöntemi ve çeşitli türevleri oluşturmaktadır (Okabe, 1926; Mononobe, 1929; Seed ve Whitman, 1970;
Richards Jr ve Elms, 1979; Nadim ve Whitman, 1983; Steedman ve Zeng, 1990). Son yillarda birtakım araştırmacılar tarafından $\mathrm{M}-\mathrm{O}$ yöntemi ve türevlerini geliştirmek adına çeşitli çalışmalar yapılmıştır (Mylonakis vd., 2007; Kloukinas vd., 2015). İkinci kategoride yer alan çalışmalara ise pek çok araştırmacı katkı sunmuştur (Matsuo, 1960; Wood, 1973, 1975; Arias vd., 1981; Veletsos ve Younan, 1994a; Veletsos ve Younan, 1994b, 1997; Younan ve Veletsos, 2000; Jung vd., 2010; Papazafeiropoulos ve Psarropoulos, 2010; Kloukinas vd., 2012; Papagiannopoulos vd., 2015; Vrettos vd., 2016). Üçüncü kategoride yer alan ve ilk iki kategorideki çalışmaların içerdiği sadeleştirici yaklaşımlardan doğan eksiklerin giderilmesi maksadıyla SEM temelli analizlerle duvarın dinamik davranışını açıklamaya yönelik pek çok çalışma literatürde mevcuttur (Wu ve Finn, 1999; Theodorakopoulos vd., 2001; Gazetas vd., 2004; Psarropoulos vd., 2005; Lanzoni vd., 2007; Madabhushi ve Zeng, 2007; Mylonakis vd., 2007; Callisto ve Soccodato, 2009; Al Atik ve Sitar, 2010; Evangelista vd., 2010; Giarlelis ve Mylonakis, 2011; Athanasopoulos-Zekkos vd., 2013; Çakır, 2013, 2014b, 2014a; Çakır ve Dağ, 2015; Çakır, 2017).

İstinat duvarlarının sismik performansını değerlendirmeye yönelik olarak genellikle birinci kategoride yer alan izin verilebilir yerdeğiştirmelere dayalı geleneksel yöntemler tercih edilmektedir. Sözde statik yöntemler olarak bilinen bu yöntemlerin en popüleri ise $\mathrm{M}-\mathrm{O}$ yöntemidir. M-O yöntemi, sözde statik şartlardaki statik Coulomb teorisinin geliştirilmiş bir şeklidir. M-O yöntemi Coulomb aktif veya pasif kamasına sözde statik ivmeler uygulanarak statik durumda duvara etkiyen itkinin deprem karakterine bağl1 olarak büyütülmesi prensibine dayanır. Daha sonra kamanın kuvvet dengesi yazılarak sözde statik zemin itkisi elde edilir. M-O yöntemi kullanışlı bir yöntem olup analizlerde güvenli tarafta kalınmasını sağlamaktadır ancak pek çok basitleştirici ve sadeleştirici yaklaşım içeren bu yöntem dalga yayılım etkilerini ve zemin-yap1 etkileşimini ihmal etmektedir. Bu sebeple güvenli tarafta kalmayı sağlasa dahi duvarın deprem etkisi altındaki gerçek davranışını açıklamakta zaman zaman eksik kalabilmektedir. Oysa istinat duvarlarının statik koşullardaki davranışının dahi zemin-yap1 etkileşiminin karmaşı bir örneği olduğu bilinmektedir. Öte yandan mevcut yönetmelikler de istinat duvarlarının sismik tasarımı hakkında sözde statik yaklaşımları içeren çözümler benimsemiş olup zemin-yap1 etkileşimi problemlerine dair herhangi bir öneri içermemektedir (IS-1893, 2002; EAK-2000, 2003; 
Eurocode-8, 2003). Ülkemizde yürürlükte olan ve bina türü yapılar için kullanılan deprem yönetmeliği (DBYBHY, 2007) de bahsi geçen karmaşık etkilere dair herhangi bir yaklaşım içermemektedir (Çakır ve Kara, 2015).

Gerek literatürdeki çalışmalar gerekse yönetmelikler 1şığında geoteknik mühendislerince gerçekleştirilen tasarımlar incelendiğinde istinat duvarlarının sismik tasarımında genellikle $\mathrm{M}-\mathrm{O}$ yöntemini temel alan sözde statik yöntemlere dayalı çalışmaların çokluğu dikkat çekmektedir. Öte yandan zemin-yapı etkileşimini dikkate alarak gerçekleştirilen pek az çalışma literatürde yer almaktadır. Ayrica zeminde yeraltı suyu bulunması durumunda duvarın davranışını ortaya koymaya yönelik çalışmaların azlığı da dikkat çekmektedir. Bu sebeple bu çalışmada bir konsol istinat duvar1-zemin sisteminin sonlu elemanlar modeli oluşturulmuş ve zemin-yap1 etkileşimini dikkate alarak duvarın sismik davranışı belirlenmiştir. $\mathrm{Bu}$ amaçla zeminin kuru olması ve 3 farklı yeraltı su seviyesine sahip olması durumları için zaman tanım alanında doğrusal olmayan bir dizi analiz gerçekleştirilmiştir. Yeraltı su seviyesindeki değişimlerin duvarın sismik davranışına etkileri elde edilmiş ve elde edilen bu sonuçlar tablolar ve grafikler halinde sunulmuştur. Duvarın davranışı yerdeğiştirmeler ve gerilmeler üzerinden irdelenmiştir. Zemin-yap1 etkileşimini değerlendirmek maksadıyla oluşturulan sonlu elemanlar modelinin sonundaki düzlemsel serbest yüzeylere viskoz sınır elemanlar uygulanmış ve daha doğru bir model oluşturabilmek adına duvar ile zemin arasına özel arayüzey elemanları uygulanmıştır.

\section{Oluşturulan Sonlu Elemanlar Modeli}

Yapılan çalışmada istinat duvarı-zemin etkileşim sisteminin sismik performansinı belirlemek maksadiyla ilk olarak sistemin iki boyutlu sonlu elemanlar modeli oluşturulmuştur. Zemin-yapı etkileşimi problemlerinde modellenecek zemin ortamı genellikle yarı sonsuz olarak düşünülür.
Yerkürenin sonsuz bir ortam olmadığı açıktır. Dış yüzeyinde gerilmeler meydana gelmeyen çok büyük bir küredir (Kramer, 1996). Yukarıda anlatılan yarı sonsuz zemin ortamı, zeminin doğrusal olmayan davranış sergilediği yapıya yakın bölgelerde "yakın bölge" ve zeminin doğrusal davranış sergilediği bölümlerde "uzak bölge" olarak iki kısma ayrılabilir (Wolf ve Song, 1996).

Yakın bölge olarak tanımlanan zemin kütlesi sonlu elemanlar ile modellenebilmektedir. Uzak bölge için ise iki yaklaşım söz konusudur. Bunlardan birincisi, hareketten etkilenen tüm zemin kütlesinin yani yap1 sistemini etkileyecek zemin ortamının tamamının sonlu elemanlar ile modellenmesidir. $\mathrm{Bu}$ durumda zemin ortamının sinırında deprem dalgalarının tamamen sönümlenmesi ve yerdeğiştirmelerin sıfırlanması veya sifira yakınsaması gerekmektedir. Modellenen zemin ortamı ne kadar büyük olursa matematik modelin gerçeğe yakınlığı da o derece artacaktır. Ancak analize konu olan zemin ortamının büyüklügüu, kullanılan eleman miktarını ve çözülmesi gereken denklem sayısını arttıracağından çözüm maliyetini de arttıracaktır. $\mathrm{Bu}$ şekilde her ne kadar gerçekçi bir çözüm yapılmış olsa da bu yöntemin pratik amaçlar için kullanımı oldukça güçtür (Nofal, 1998). İkinci yöntem ise, yarı sonsuz zemin ortamının sonunda zeminin sürekliliğini temsil edecek şekilde sanal sinırlar kullanılmasıdır. $\mathrm{Bu}$ uygulamayla yayılmaya bağlı sönüm ve yansıma gibi etkilerin dikkate alınabilmesi mümkündür. Sanal sınır kullanımları, oluşturulan zemin modelinin boyutlarını küçülttüğü için işlem kolaylığı sağlamakta ve çözüm maliyetini düşürmektedir. Buna ilaveten zemin-yapı etkileşiminin doğru şekilde temsil edilmesine olanak sağlayarak gerçekçi bir çözüm sunmaktadır (Çakır, 2013). Bu çalışmada, oluşturulan modelde yakın bölge zemininin sonundaki düzlemsel serbest yüzeye viskoz sanal sınırlar uygulanmıştır (Lysmer ve Kuhlemeyer, 1969).

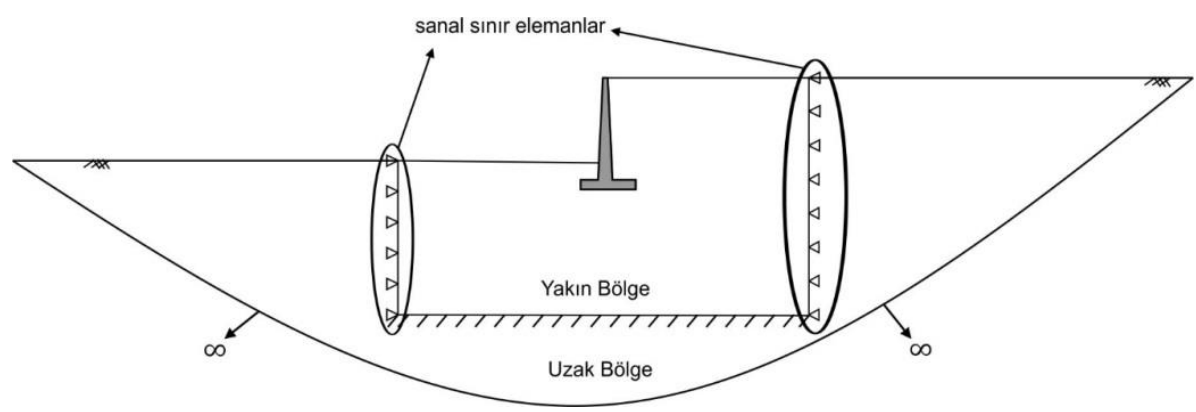

Şekil 1. Oluşturulan modelin şematik gösterimi 
Analizlerde kullanılan istinat duvarının geometrisi; düşey gövde plağının yüksekliği 5.3 metre ve duvarın mesnetlendiği yatay temel plağının yüksekliği 0.5 metre olmak üzere toplam 5.8 metre olup duvarın mesnetlendiği yatay temel plağının genişliği 2.6 metredir. Duvarın ön ampatman genişliği 0.9 metre ve arka ampatman genişliği 1.2 metredir. Ayrıca duvar genişliği üst noktada 0.25 metre ve temel taban plağına birleştiği alt noktada 0.5 metre olacak şekilde ele alınmıştır.

Oluşturulan sonlu elemanlar modelinde zemin ve duvar plane strain elemanlarla modellenmiştir. Oluşturulan modelde dolgu ve temel zemininin malzeme özellikleri aynıdır. Zemin ile duvar arasındaki davranışı daha doğru modelleyebilmek adına Coulomb'un sürtünme yasasını temel alan doğrusal olmayan özel arayüzey elemanları kullanılmıştır. Ayrıca zeminin doğrusal olmayan davranışı Mohr-Coulomb bünye modeliyle temsil edilmiştir. Zemin-yap1 etkileşimi probleminin çözümünde doğrudan çözüm yöntemlerinden sonlu elemanlar yöntemi kullanılmıştır. Literatüre bakıldığında modellenecek yarı sonsuz zemin ortamının duvar yüksekliğinin 10 katı olacak şekilde ele alınması uygun görülmektedir (Veletsos ve Younan, 1994a; Psarropoulos vd., 2005). Bu çalışma özelinde, analiz sürelerini kısaltmak adına bir takım parametrik çalışma yapılmıştır ve Şekil 2'de önerilen modelin sonuçlarıyla literatürde önerilen boyutların arasında anlamlı bir farklılık meydana gelmediği görülerek analizler zaman tasarrufu sağlamak adına bu model üzerinden gerçekleştirilmiştir.

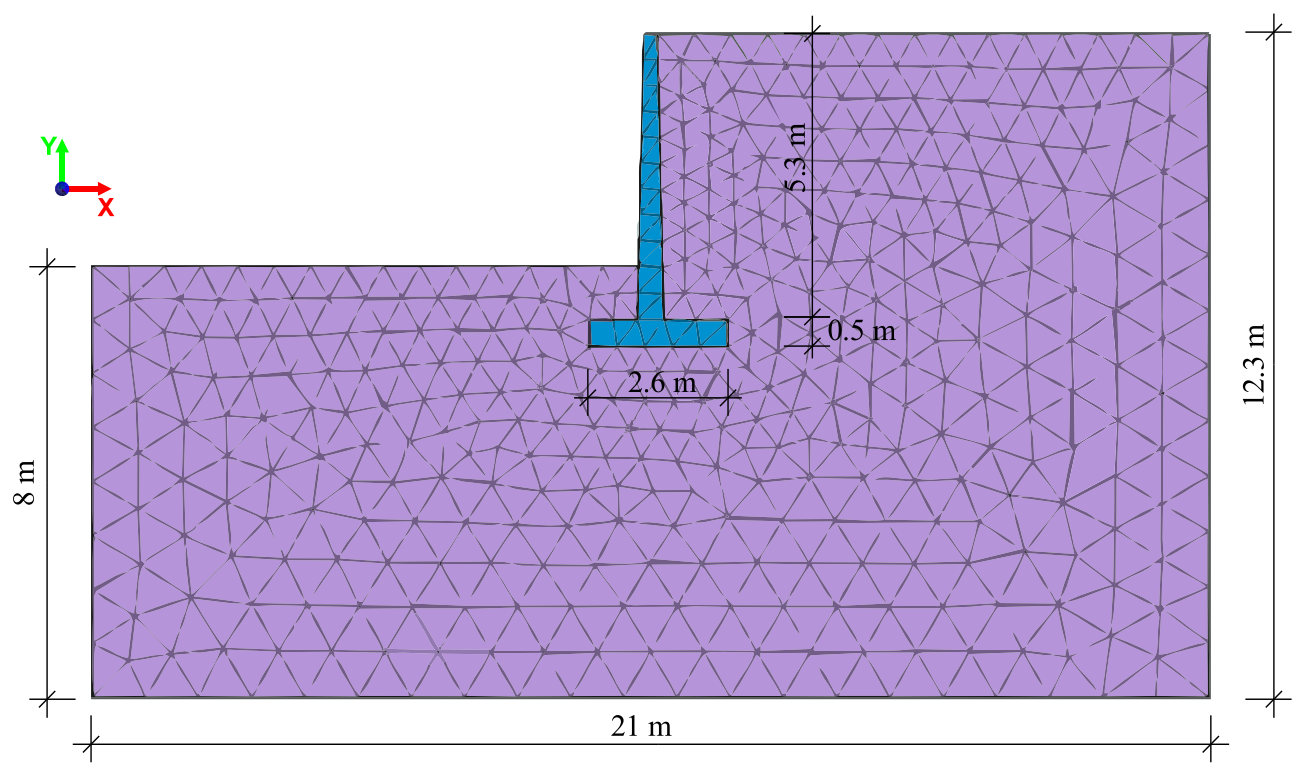

Şekil 2. Oluşturulan sonlu elemanlar modeli

\section{Sismik Analiz}

İstinat duvar1-zemin sisteminin sonlu elemanlar modelinin oluşturulmasının ardından yeraltı su seviyesinde meydana gelen değişimlerin duvarın dinamik davranışı üzerindeki etkilerini değerlendirmek amaciyla zaman tanım alanında doğrusal olmayan çözümlemeler yapılmıştır. Zaman tanım alanında doğrusal olmayan analiz, belirli bir ivme kaydına göre yapı/zeminde meydana gelen elastik ötesi davranışı elde etmek için kullanılır. Doğrusal olmayan analizler, deprem yükü altındaki yapıların sismik davranışını elde etmede en gerçekçi yöntem olarak değerlendirilmektedir. İki boyutlu doğrusal olmayan dinamik tepki analizleri, artışlı şekilde idealleştirilmiş sonlu elemanlardan hareketin global denklemlerinin yazılmasının ardından zaman tanım alanında integralinin alınmasıyla gerçekleştirilir (Kramer, 1996). Matematiksel olarak zaman tanım alanında analizler, doğrudan entegrasyonun kullanımıyla yapılabilmektedir. Doğrudan entegrasyon yöntemi, zaman tanım alanında dinamik analizler için en doğru sonuçları veren metottur. $\mathrm{Bu}$ yöntemde, dinamik yükler yapıya $\Delta \mathrm{t}$ zaman aralıklarında artımsal olarak etkitilmektedir ve zaman tanım alanında denklemlerin çözümü nümerik olarak doğrudan entegrasyon yöntemiyle gerçekleştirilmektedir (Korkmaz ve Düzgün, 2011). Zaman tanım alanından doğrusal olmayan analizlerden önce sistemin özdeğer analizleri yapılarak doğal periyotları belirlenmiştir. Sistemin sönüm sabiti $\% 5$ seçilmiştir. Elde edilen bu veriler doğrusal 
olmayan analizlerde kullanılmıştır. Yapılan tüm bu analizlerde Midas Gts Nx sonlu elemanlar yazılımından faydalanılmıştır. Analizlerde, yazılımın kütüphanesinde bulunan ve Şekil 3'te ivme-zaman grafiği görülen San Fernando Pacoima Dam depremine ait kayıt kullanılmıştır. $\mathrm{Bu}$ depreme ait en büyük yer ivmesi $1.0748 \mathrm{~g}$ olarak ölçülmüş̧ür.

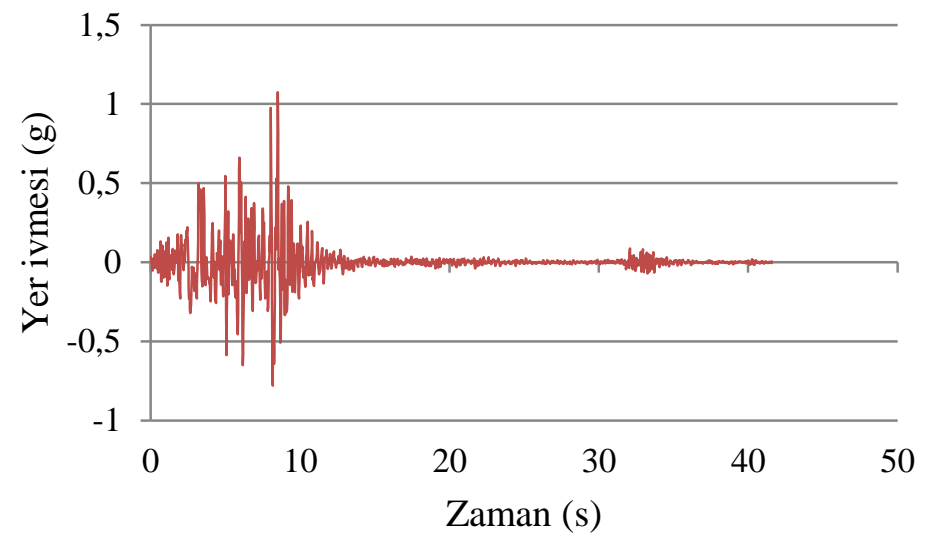

Şekil 3. San Fernando Pacoima Dam depremine ait ivme-zaman grafiği

İlk olarak zemin ortamında yeraltı suyunun bulunmamas1 durumunda ( $Z 1$ durumu) ve daha sonra sırasılyla temel taban plağı genişliği 2.6 metre olan duvarda temel taban plağı genişliği kadar aşağıda yeraltı suyu bulunması durumu (Z2 durumu), temel tabaniyla aynı seviyede yeraltı suyu bulunmas1 durumu ( $\mathrm{Z} 3$ durumu) ve son olarak duvar arkasındaki dolgunun en üst kotundan $2 \mathrm{~m}$. aşağıda yeraltı suyu bulunması durumu (Z4 durumu) olmak üzere 4 farklı durum için duvarın dinamik davranışı değerlendirilmiştir. Gerçekleştirilen analizlerde yeraltı su seviyelerinin sabit olduğu, zeminde sıvılaşma meydana gelmediği ve duvarın geçirimsiz olduğu kabul edilmiştir.

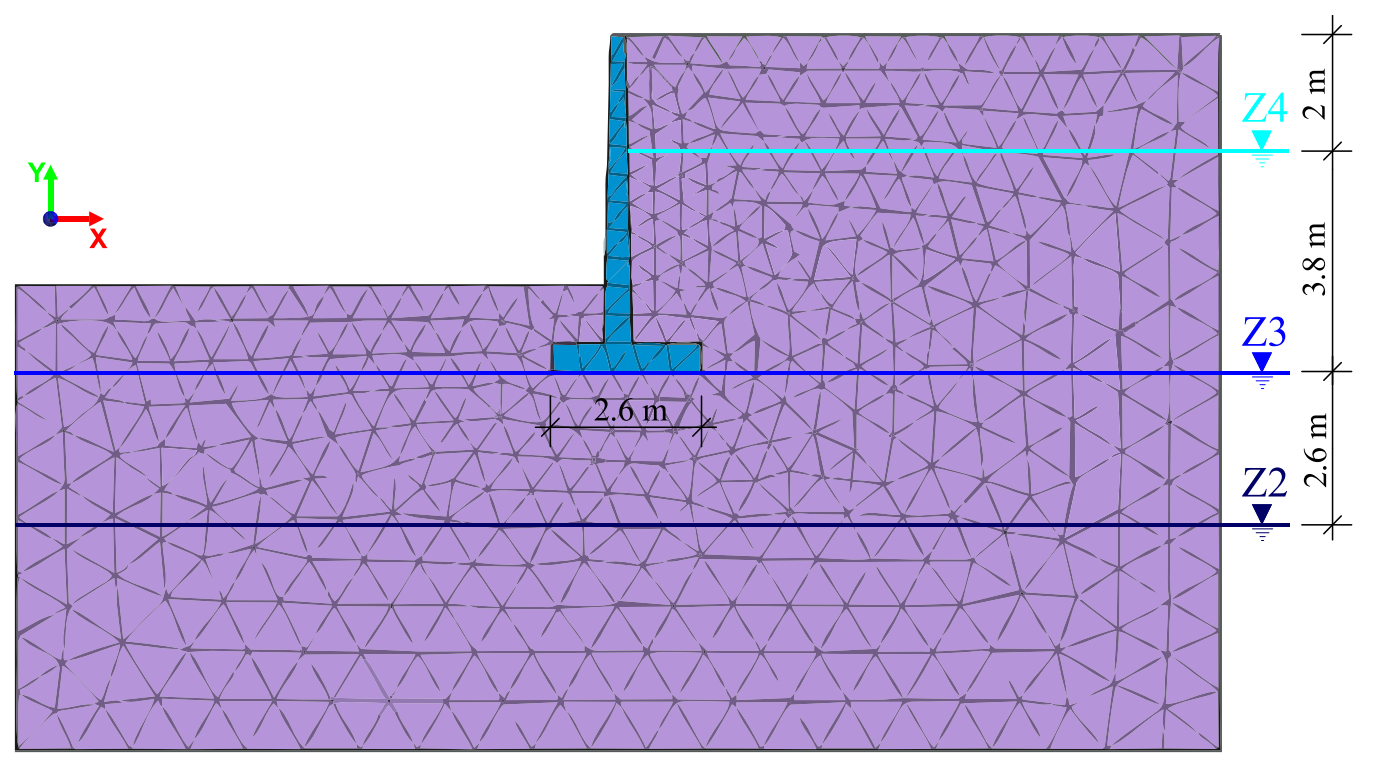

Şekil 4. Dikkate alınan yeraltı su seviyelerinin şematik gösterimi

Analize konu olan istinat duvarına ait malzeme özellikleri Tablo 1'de, ayrıca analizde kullanılan kohezyonsuz zemine ait malzeme özellikleri de Tablo 2'de sunulmaktadır.
Tablo 1. Analize konu olan istinat duvarına ait malzeme özellikleri

\begin{tabular}{cccc}
\hline $\mathrm{E}(\mathrm{kPa})$ & $\mathrm{G}(\mathrm{kPa})$ & $v$ & $\gamma\left(\mathrm{kN} / \mathrm{m}^{3}\right)$ \\
\hline 32000000 & 13333333.3 & 0.2 & 24 \\
\hline
\end{tabular}


Tablo 2. Analize konu olan zemin sistemine ait malzeme özellikleri

\begin{tabular}{cccccccc}
\hline \multirow{2}{*}{ Zemin Özellikleri } & $\mathrm{E}(\mathrm{kPa})$ & $\mathrm{G}(\mathrm{kPa})$ & $v$ & $\begin{array}{c}\gamma \\
\left(\mathrm{kN} / \mathrm{m}^{3}\right)\end{array}$ & $\begin{array}{c}\gamma_{\mathrm{d}} \\
\left(\mathrm{kN} / \mathrm{m}^{3}\right)\end{array}$ & $\begin{array}{c}\mathrm{V}_{\mathrm{s}} \\
(\mathrm{m} / \mathrm{s})\end{array}$ & $\mathrm{V}_{\mathrm{p}}(\mathrm{m} / \mathrm{s})$ \\
\cline { 2 - 8 } & 50000 & 17857.1429 & 0.4 & 18 & 21 & 99.6 & 243.97 \\
\hline
\end{tabular}

\section{Bulgular ve Değerlendirmeler}

Zeminin tamamen kuru olması ve 3 farklı yeraltı su seviyesi bulunması durumları için yapılan sismik analizlerden elde edilen sonuçlarla duvarın dinamik davranışı yerdeğiştirmeler ve gerilmeler üzerinden değerlendirilmiştir. Duvar üzerinde meydana gelen en büyük yerdeğiştirmeler ve gerilmeler gerçekleşme zamanlarıyla birlikte Tablo 3'te sunulmaktadır. Burada bahsi geçen yerdeğiştirmeler, yer seviyesine göre meydana gelen rölatif yerdeğiştirmelerdir ve her durumda duvar üzerindeki en büyük yerdeğiştirme tepe noktada meydana gelmiştir.

Tablo 3. Duvarda meydana gelen en büyük tepkiler ve gerçekleşme zamanları

\begin{tabular}{|c|c|c|c|c|c|c|c|c|}
\hline \multirow{3}{*}{ En Büyük Tepkiler } & \multicolumn{8}{|c|}{ Zemin Sistemi } \\
\hline & \multicolumn{2}{|c|}{$\mathrm{Z1}$} & \multicolumn{2}{|c|}{$\mathrm{Z2}$} & \multicolumn{2}{|c|}{$\mathrm{Z3}$} & \multicolumn{2}{|c|}{$\mathrm{Z4}$} \\
\hline & $\mathrm{t}(\mathrm{s})$ & Değer & $\mathrm{t}(\mathrm{s})$ & Değer & $t(s)$ & Değer & $\mathrm{t}(\mathrm{s})$ & Değer \\
\hline $\mathrm{d}_{\mathrm{t}}(\mathrm{m})$ & 6.2 & 0.022 & 8.7 & 0.028 & 6.2 & 0.032 & 17.8 & 0.23 \\
\hline $\mathrm{S}_{\text {xö }}(\mathrm{kPa})$ & 6.4 & -107.622 & 8.6 & -105.368 & 8.6 & -134.076 & 3.2 & -162.75 \\
\hline $\mathrm{S}_{\text {yö }}(\mathrm{kPa})$ & 6.4 & -611.975 & 8.6 & -615.261 & 8.6 & -728.635 & 3.2 & -746.586 \\
\hline $\mathrm{S}_{\mathrm{xa}}(\mathrm{kPa})$ & 6.4 & 95.343 & 8.6 & 100.968 & 8.6 & 122.396 & 3.2 & 125.616 \\
\hline $\mathrm{S}_{\mathrm{ya}}(\mathrm{kPa})$ & 8.6 & 490.521 & 8.6 & 540.419 & 8.6 & 572.874 & 3.2 & 649.619 \\
\hline
\end{tabular}

Burada $d_{t}$ : en büyük yerdeğiştirmeyi, $S_{x \ddot{x}}$ ve $S_{x a}$ sirasiyla duvarın ön ve arka yüzünde $x$ doğrultusunda meydana gelen en büyük gerilmeyi, $S_{\mathrm{yö}}$ ve $S_{\mathrm{ya}}$ sirasıyla duvarın ön ve arka yüzünde y doğrultusunda meydana gelen en büyük gerilmesi ve $\mathrm{t}$ ise bu tepkilerin gerçekleşme zamanlarını göstermektedir.
Duvar üzerinde meydana gelen yerdeğiştirmeler temel taban plağından duvarın tepe noktasına doğru artan bir biçimde meydana gelmiştir. Duvar yüksekliği boyunca duvarda yer seviyesine göre meydana gelen rölatif yerdeğiştirmeler Şekil 5'te görülmektedir.

Şekil 5. İstinat duvarının farklı yeraltı su seviyelerinde rölatif yatay yerdeğiştirmelerinin yükseklik boyunca değişimi

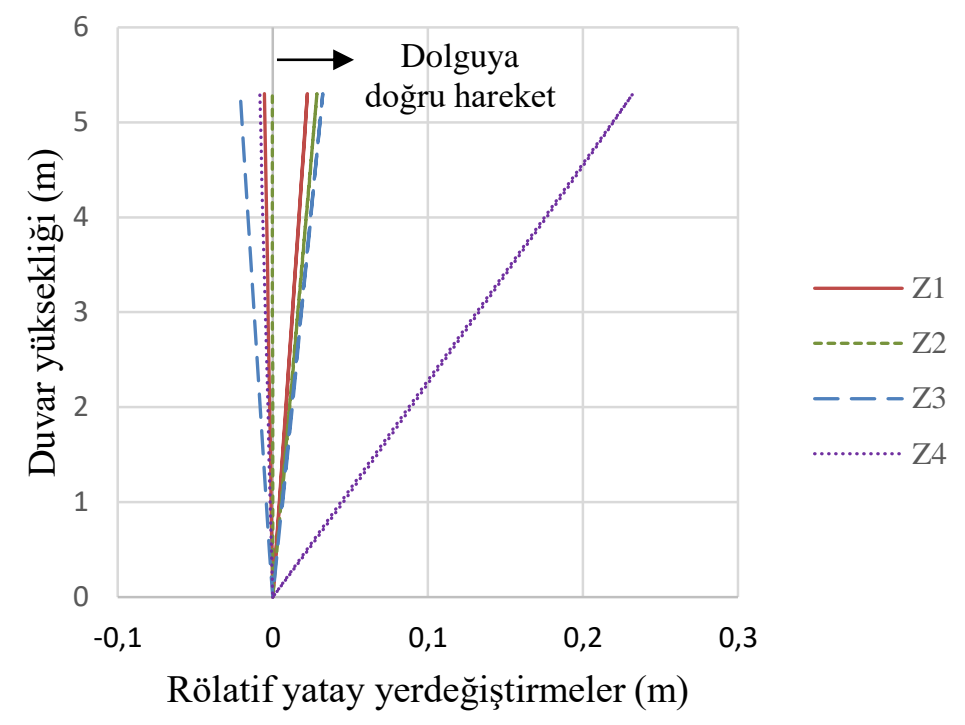

Duvarda yeraltı suyunun bulunmadığ $\mathrm{Z} 1$ zemin sistemi için en büyük yerdeğiştirme 6.2 saniyede 0.022 metre, yeralt1 su seviyesinin temel taban plağının alt kotundan, temel taban plağı genişliği kadar aşağıda olduğu Z2 zemin sistemi için 8.7 saniyede 0.028 metre, yeraltı suyunun temel taban 
plağıyla aynı seviyede olduğu Z3 zemin sistemi için 6.2 saniyede 0.032 metre ve yeraltı suyunun duvarın arkasında, dolgu zemininin en üst kotundan 2 metre aşağıda olduğu $\mathrm{Z4}$ zemin sistemi için 17.8 saniyede 0.23 metre olarak oluşmuştur. Duvarda oluşan en büyük yatay yerdeğiştirmelerin, Z1 zemin sistemindeki en büyük yatay yerdeğiştirmeye oranla Z2 zemin sisteminde \%27 civarında, Z3 zemin sisteminde \%45 civarında ve Z4 zemin sisteminde yaklaşık 10 kat artış gösterdiği görülmektedir. Yerdeğiştirmeler Z4 durumu hariç genel olarak benzer tipte oluşmuştur ancak en büyük değerleri farklılıklar göstermektedir. Yeraltı su seviyesinin yükselmesiyle duvarın yatay yerdeğiştirmeleri ciddi oranda artış göstermekte olup özellikle yeraltı suyunun duvarın arkasına ulaşması durumunda çok büyük değerlere ulaşmaktadır. İstinat duvarları dolgu arkasında su birikmesini önleyecek şekilde gerekli drenaj önlemleri alınarak inşa edilmektedir ancak herhangi bir sebeple drenaj sisteminin işlevini yitirmesi veya yeterli drenajı sağlayamaması durumunda duvarda meydana gelen yerdeğiştirmeler çok büyük değerlere ulaşmaktadır. Ayrıca bu analizde duvarın hareketi hem dolguya hem de dolgudan uzağa doğru gerçekleşmiş olup her durum için en büyük yerdeğiştirme dolguya doğru hareket sırasında gerçekleşmiştir. Şekil 6'da duvarın tepe noktasının yaptığı rölatif yerdeğiştirmelerin zamanla değişimi gösteren grafik sunulmaktadır.

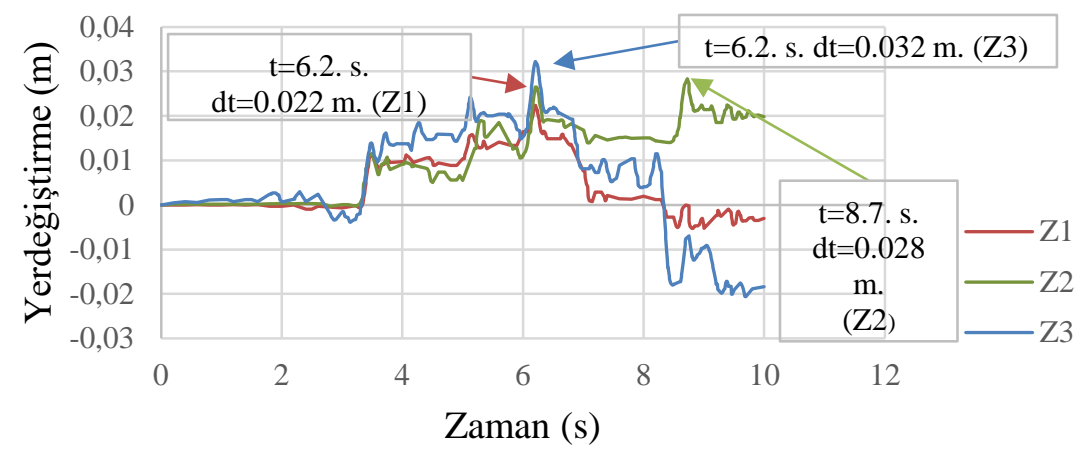

Şekil 6. İstinat duvarının farklı yeraltı su seviyelerine göre tepe noktasının yerdeğiştirmeleri

Yeraltı su seviyesinin duvarın arkasına ulaştığı Z4 durumu hariç duvarda meydana gelen yerdeğiştirmeler genel itibariyle benzer tipte meydana gelmiştir ancak Z4 durumunda çok farklı bir yerdeğiştirme davranışı gözlenmiştir.

Yeraltı su seviyesindeki farklılıkların duvarın dinamik davranışına etkisini değerlendirmek maksadıyla irdelenen bir diğer etki duvarın ön ve arka yüzünde $\mathrm{x}$ ve $\mathrm{y}$ doğrultusunda oluşan gerilmelerdir. Duvarın ön yüzünde $x$ doğrultusunda oluşan gerilmeler Z1 zemin sistemi için 6.4 saniyede $-107.622 \mathrm{kPa}$ büyüklügünde çekme gerilmesi, Z2 zemin sistemi için 8.6 saniyede $-105.368 \mathrm{kPa}$ büyüklügünde çekme gerilmesi, Z3 zemin sistemi için 8.6 saniyede $134.076 \mathrm{kPa}$ büyüklüğünde çekme gerilmesi ve Z4 zemin sistemi için 3.2 saniyede $-162.75 \mathrm{kPa}$ büyüklüğünde çekme gerilmesi olarak oluşmuştur (Şekil 7). Yine duvarın ön yüzünde $y$ doğrultusunda meydana gelen gerilmeler Z1 zemin sistemi için 6.4 saniyede $-611.975 \mathrm{kPa}$ büyüklüğünde çekme gerilmesi, Z2 zemin sistemi için 8.6 saniyede $-615.261 \mathrm{kPa}$ büyüklügünde çekme gerilmesi, Z3 zemin sistemi için 8.6 saniyede $-728.635 \mathrm{kPa}$ büyüklügünde çekme gerilmesi ve Z4 zemin sistemi için 3.2 saniyede $746.586 \mathrm{kPa}$ büyüklüğünde çekme gerilmesi olarak oluşmuştur (Şekil 8). Duvarın ön yüzünde meydana gelen gerilmeler genel olarak benzer tipte meydana gelmiştir ve büyüklükleri birbirinden farklıdır. Duvarın ön yüzünde meydana gelen gerilmelerin gerçekleşme zamanları her bir zemin sınıfı için aynıdır.

Duvarın arka yüzünde $\mathrm{x}$ doğrultusunda meydana gelen gerilmeler ise $\mathrm{Z1}$ zemin sistemi için 6.4 saniyede $95.343 \mathrm{kPa}$ büyüklüğünde basınç gerilmesi, $\mathrm{Z} 2$ zemin sistemi için 8.6 saniye $100.968 \mathrm{kPa}$ büyüklüğünde basınç gerilmesi, Z3 zemin sistemi için 8.6 saniyede $122.396 \mathrm{kPa}$ büyüklügüünde basınç gerilmesi ve $\mathrm{Z4}$ zemin sistemi için 3.2 saniyede $125.616 \mathrm{kPa}$ büyüklüğünde basınç gerilmesi olarak oluşmuştur (Şekil 9). Duvarın arka yüzünde y doğrultusundaki gerilmeler ise $\mathrm{Z} 1$ zemin sistemi için 8.6 saniyede $490.521 \mathrm{kPa}$ 
büyüklüğünde basınç gerilmesi, Z2 zemin sistemi için 8.6 saniyede $540.419 \mathrm{kPa}$ büyüklüğünde basınç gerilmesi, $\mathrm{Z3}$ zemin sistemi için 8.6 saniyede $572.874 \mathrm{kPa}$ büyüklüğünde basinç gerilmesi ve $\mathrm{Z4}$ zemin sistemi için 3.2 saniyede $649.619 \mathrm{kPa}$ büyüklüğünde basınç gerilmesi olarak oluşmuştur (Şekil 10).

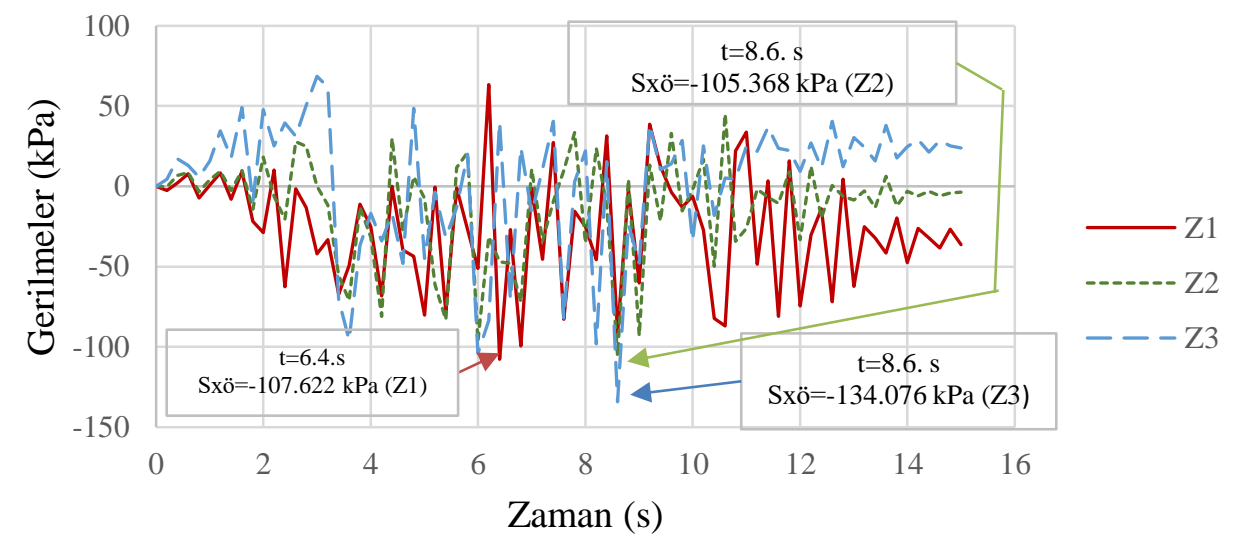

Şekil 7. Duvarın ön yüzünde x doğrultusunda meydana gelen gerilmeler

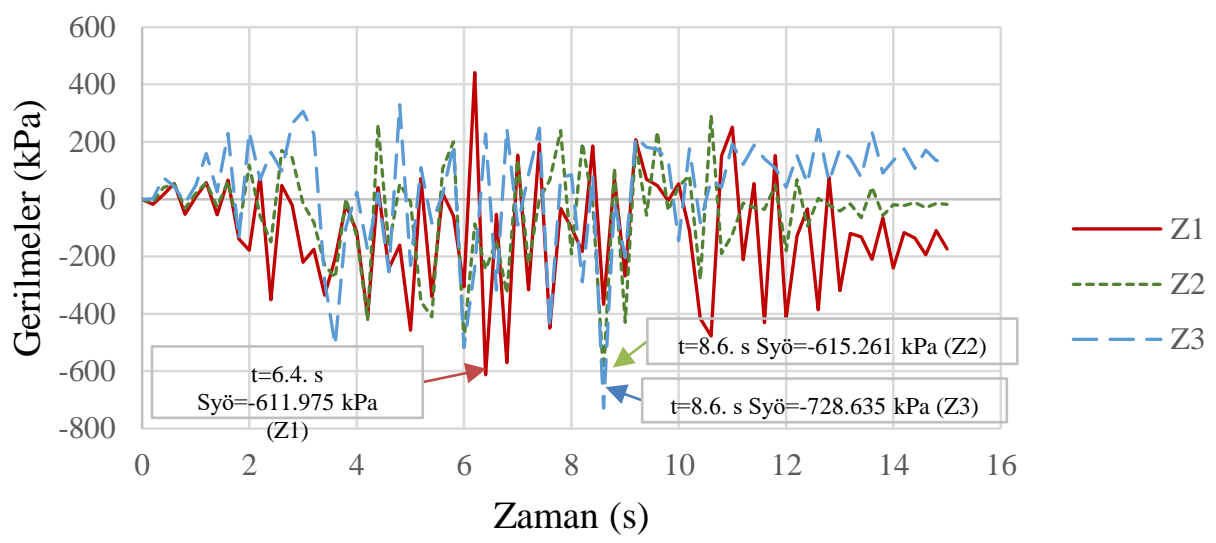

Şekil 8. Duvarın ön yüzünde y doğrultusunda meydana gelen gerilmeler

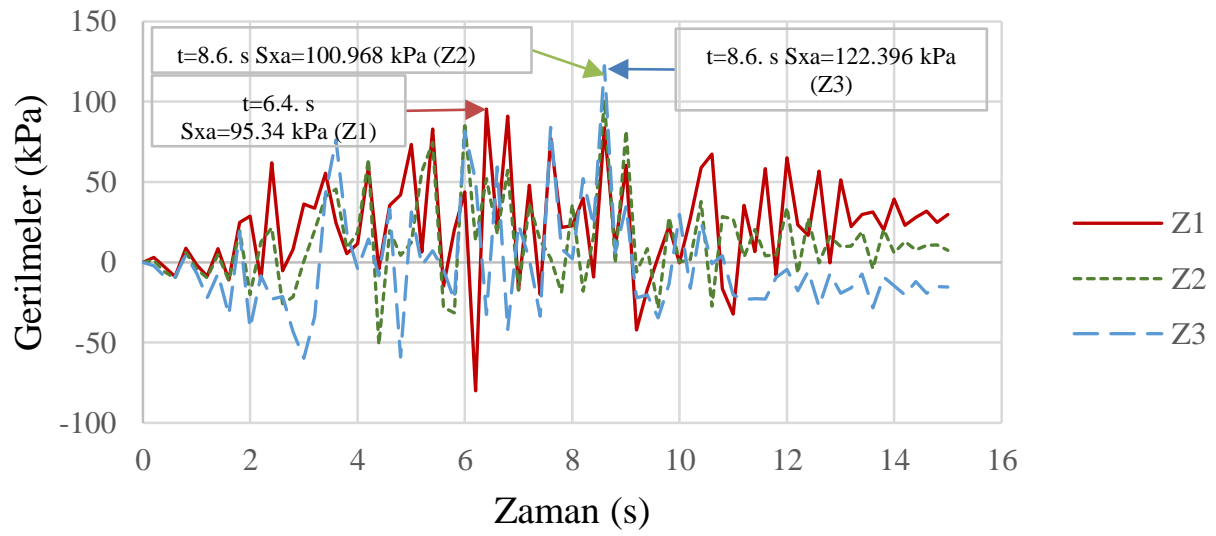

Şekil 9. Duvarın arka yüzünde x doğrultusunda meydana gelen gerilmeler 


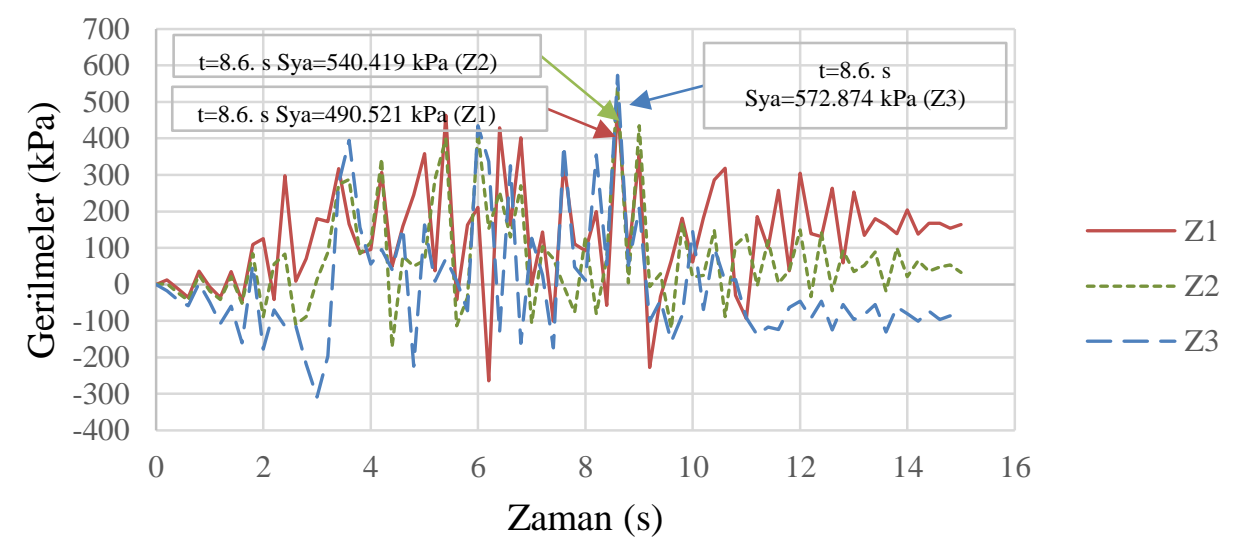

Şekil 10. Duvarın arka yüzünde y doğrultusunda meydana gelen gerilmeler

\section{Sonuçlar ve Öneriler}

Elde edilen sonuçlar, oluşturulan istinat duvar1zemin sisteminin sismik davranışına zemin-yapı etkileşiminin ve yeraltı suyunun etkilerini açıkça ortaya koymaktadır. Zeminde yeraltı su seviyesinin yükselmesine bağlı olarak duvarın yatay yerdeğiştirmelerinde önemli miktarda artış meydana gelmektedir. Bu analiz çerçevesinde ele alınan istinat duvarı-zemin sisteminde meydana gelen yatay yerdeğiştirmeler hem dolgu yönünde hem de dolgunun tersi yönde oluşmuştur. Buradan istinat duvarlarının yerdeğiştirmeye oldukça duyarlı yapılar olduğu bir kez daha görülmektedir. $\mathrm{Z1}, \mathrm{Z} 2$ ve $\mathrm{Z3}$ zemin sistemlerinde duvar hareketi genel itibariyle benzer tipte oluşurken yeraltı suyunun duvarın arkasına ulaştığı Z4 zemin sisteminde oluşan duvar hareketi diğer durumlarla benzerlik göstermemektedir. İstinat duvarlarının inşa aşamasında duvarın arkasında bırakılan drenlerle duvar arkasındaki zeminin drenaj1 sağlanmaktadır. Z4 zemin sistemi için elde edilen sonuçlar neticesinde, istinat duvarlarının inşasında drenajın oldukça önemli olduğu ve duvarın tasarımında drenaj sistemlerinin çok dikkatli bir şekilde ele alınması gerekliliği açıkça görülmektedir. Drenajların muhtelif sebeplerle işlev göremez hale gelmesi duvarın yatay yerdeğiştirmelerini kabul edilemez ölçülerde etkileyebilmektedir. Ayrıca yeraltı su seviyesinin duvarın arkasına ulaşmadığı durumlarda dahi zemindeki boşluk suyu basıncı artışının duvarın hareketini ciddi mertebelerde etkilediği görülmektedir. $\mathrm{Bu}$ sonuçlar göstermektedir ki duvarın inşa edileceği alanlarda yeraltı suyunun bulunması durumunda duvarın tasarımında yeraltı suyunun etkilerinin de dikkate alınması gerekmektedir. $\mathrm{Bu}$ etkiler duvarın güvenliğini tehlikeye atacak boyutlara ulaştı̆̆ında gerekirse yeraltı su seviyesinin düşürülmesi yoluna gidilmesi önerilmektedir. Bu sonuçlar neticesinde istinat duvarının hareketinde yeraltı suyunun, yerel zemin koşullarının, zemin-yapı etkileşiminin önemi bir kez daha görülmektedir.

Yerdeğiştirmelerde olduğu gibi, yeraltı su seviyesinin yükselmesi duvar üzerindeki gerilmeleri de önemli mertebelerde etkilemektedir. Yeraltı suyunun yükselmesine bağlı olarak duvar üzerindeki gerilmeler genellikle artma eğilimindedir. Ancak bu değişimlerin hangi yeraltı su seviyelerinde nasıl değişimler ortaya koyacağı konusunda genelleştirilebilecek bir kanıya varmak için daha farkl 1 yeraltı su seviyelerine sahip, farkl özelliklerdeki zeminlerde, farklı geometri ve rijitlikteki duvarlar için ve farklı frekanslardaki deprem kayıtlarına göre çok daha fazla parametrik çalışma yapılması gerekmektedir.

\section{Kaynaklar}

Al Atik, L. ve Sitar, N., 2010. Seismic earth pressures on cantilever retaining structures. Journal of Geotechnical and Geoenvironmental Engineering, 136(10), 1324-1333

Arias, A., Sanchez-Sesma, F. ve Ovando-Shelley, E., 1981. A simplified elastic model for seismic analysis of earth-retaining structures with limited displacements.

Athanasopoulos-Zekkos, A., Vlachakis, V. ve Athanasopoulos, G., 2013. Phasing issues in the seismic response of yielding, gravity-type earth retaining walls-Overview and results from a FEM study. Soil Dynamics and Earthquake Engineering, 55, 59-70

Callisto, L. ve Soccodato, F., 2009. Seismic design of flexible cantilevered retaining walls. Journal of Geotechnical and Geoenvironmental Engineering, 136(2), 344-354 
Canbay, E., Özcebe, G., Sucuoğlu, H., Wasti, T. ve Ersoy, U., 2008. Binalar İçin Deprem Mühendisliği Temel İlkeler. ODTÜ Geliştirme Vakfi Yayıncılık, Ankara

Çakır, T., 2013. Evaluation of the effect of earthquake frequency content on seismic behavior of cantilever retaining wall including soil-structure interaction. Soil Dynamics and Earthquake Engineering, 45, 96-111

Çakır, T., 2014a. Backfill and subsoil interaction effects on seismic behavior of a cantilever wall. Geomechanics and Engineering, 6(2), 117-138

Çakır, T., 2014b. Influence of wall flexibility on dynamic response of cantilever retaining walls. Structural Engineering and Mechanics, 49(1), 122

Çakır, T., 2017. Assessment of effect of material properties on seismic response of a cantilever wall. Geomechanics and Engineering, 13(4), 601-619

Çakır, T. ve Dağ, S., 2015. Zemin-Yapı Etkileşimi ve Duvar Esnekliği Dikkate Alınarak Konsol İstinat Duvarlarının Dinamik Yerdeğiştirme ve Gerilme Analizi. Sigma, 33(4), 577-589

Çakır, T. ve Kara, O., 2015. Dolgu Zeminine Ait Birim Hacim Ağırlık Değeri Değişiminin Konsol Bir İstinat Duvarının Sismik Davranışı Üzerindeki Etkileri. Gümüşhane Üniversitesi Fen Bilimleri Enstitüsü Dergisi, 5(2), 87-100

DBYBHY, 2007. Deprem Bölgelerinde Yapılacak Binalar Hakkında Yönetmelik. T.C. Çevre ve Şehircilik Bakanlığı, Afet İşleri Genel Müdürlüğü, Deprem Araştırma Dairesi

EAK-2000, 2003. Greek Seismic Code, Earthquake Planning and Protection Organization, Athens.

Eurocode-8, 2003. Design of Structures for Eathquake Resistance - Part 5: Foundations, Retaining Structures and Geotechnical Aspects, European Comittee for Standardization, Brussel, Belgium.

Evangelista, A., di Santolo, A. S. ve Simonelli, A. L., 2010. Evaluation of pseudostatic active earth pressure coefficient of cantilever retaining walls. Soil Dynamics and Earthquake Engineering, 30(11), 1119-1128

Gazetas, G., Psarropoulos, P., Anastasopoulos, I. ve Gerolymos, N., 2004. Seismic behaviour of flexible retaining systems subjected to shortduration moderately strong excitation. Soil Dynamics and Earthquake Engineering, 24(7), 537-550

Giarlelis, C. ve Mylonakis, G., 2011. Interpretation of dynamic retaining wall model tests in light of elastic and plastic solutions. Soil Dynamics and Earthquake Engineering, 31(1), 16-24

IS-1893, 2002. Indian Standart Criteria for Earthquake Resistant Design of Structures. General Provisions and Buildings (Fifth Revision). Part 1,2002

Jung, C., Bobet, A. ve Fernández, G., 2010. Analytical solution for the response of a flexible retaining structure with an elastic backfill. International Journal for Numerical and Analytical Methods in Geomechanics, 34(13), 1387-1408

Kloukinas, P., di Santolo, A. S., Penna, A., Dietz, M., Evangelista, A., Simonelli, A. L., Mylonakis, G., 2015. Investigation of seismic response of cantilever retaining walls: Limit analysis vs shaking table testing. Soil Dynamics and Earthquake Engineering, 77, 432-445

Kloukinas, P., Langousis, M. ve Mylonakis, G., 2012. Simple wave solution for seismic earth pressures on nonyielding walls. Journal of Geotechnical and Geoenvironmental Engineering, 138(12), 1514-1519

Korkmaz, A. ve Düzgün, M., 2011. Doğrusal olmayan yapısal analiz yöntemlerinin değerlendirilmesi. İTÜDERGİSİ/d, 6(3)

Kramer, S. L., 1996. Geotechnical Earthquake Engineering Prentice Hall. New York

Lanzoni, L., Radi, E. ve Tralli, A., 2007. On the seismic response of a flexible wall retaining a viscous poroelastic soil. Soil Dynamics and Earthquake Engineering, 27(9), 818-842

Lysmer, J. ve Kuhlemeyer, R. L., 1969. Finite dynamic model for infinite media. Journal of the Engineering Mechanics Division, 95(4), 859878

Madabhushi, S. ve Zeng, X., 2007. Simulating seismic response of cantilever retaining walls. Journal of Geotechnical and Geoenvironmental Engineering, 133(5), 539-549

Matsuo, H., 1960. Lateral earth pressure and stability of quay walls during earthquakes, Proc. of 2nd WCEE, s.165-183.

Mononobe, N., 1929. On determination of earth pressure during earthquake, Proc. of the World Engineering Congress, Tokyo, s.177-185.

Mylonakis, G., Kloukinas, P. ve Papantonopoulos, C., 2007. An alternative to the Mononobe-Okabe equations for seismic earth pressures. Soil Dynamics and Earthquake Engineering, 27(10), 957-969 
Nadim, F. ve Whitman, R. V., 1983. Seismically induced movement of retaining walls. Journal of Geotechnical Engineering, 109(7), 915-931

Nofal, E. M. H., 1998. Analysis of Non-lineer Soil-Pile Interaction Under Dynamic Lateral Loading. Phd Thesis, University of California. Irvine.

Okabe, S., 1926. General theory of earth pressures, J. Japan Soc. Civil Engineering, 12(1)

Özmen, B., Güler, H. ve Nurlu, M., 1997. Coğrafi bilgi sistemi ile deprem bölgelerinin incelenmesi, Bayındırlık ve İskan Bakanlığı Afet İşleri Genel Mürdürlüğü.

Papagiannopoulos, G., Beskos, D. ve Triantafyllidis, T., 2015. Seismic pressures on rigid cantilever walls retaining linear poroelastic soil: An exact solution. Soil Dynamics and Earthquake Engineering, 77, 208-219

Papazafeiropoulos, G. ve Psarropoulos, P. N., 2010. Analytical evaluation of the dynamic distress of rigid fixed-base retaining systems. Soil Dynamics and Earthquake Engineering, 30(12), 1446-1461

Psarropoulos, P., Klonaris, G. ve Gazetas, G., 2005. Seismic earth pressures on rigid and flexible retaining walls. Soil Dynamics and Earthquake Engineering, 25(7), 795-809

Richards Jr, R. ve Elms, D. G., 1979. Seismic behavior of gravity retaining walls. Journal of Geotechnical and Geoenvironmental Engineering, 105(ASCE 14496)

Seed, H. B. ve Whitman, R. V., 1970. Design of earth retaining structures for dynamic loads. ASCE, Specialty Conf on Lateral Stresses in Ground and Design of Earth-Retaining Structures; Ithaca, NY, 103-147

Steedman, R. ve Zeng, X., 1990. The influence of phase on the calculation of pseudo-static earth pressure on a retaining wall. Geotechnique, 40(1), 103-112
Theodorakopoulos, D., Chassiakos, A. ve Beskos, D., 2001. Dynamic pressures on rigid cantilever walls retaining poroelastic soil media. Part I. First method of solution. Soil Dynamics and Earthquake Engineering, 21(4), 315-338

Veletsos, A. ve Younan, A., 1994a. Dynamic soil pressures on rigid vertical walls. Earthquake engineering \& structural dynamics, 23(3), 275301

Veletsos, A. S. ve Younan, A. H., 1994b. Dynamic modeling and response of soil-wall systems. Journal of Geotechnical Engineering, 120(12), 2155-2179

Veletsos, A. S. ve Younan, A. H., 1997. Dynamic response of cantilever retaining walls. Journal of Geotechnical and Geoenvironmental Engineering, 123(2), 161-172

Vrettos, C., Beskos, D. ve Triantafyllidis, T., 2016. Seismic pressures on rigid cantilever walls retaining elastic continuously non-homogeneous soil: an exact solution. Soil Dynamics and Earthquake Engineering, 82, 142-153

Wolf, J. P. ve Song, C., 1996. Finite-element modelling of unbounded media, Wiley Chichester.

Wood, J. H., 1973. Earthquake-induced soil pressures on structures.

Wood, J. H., 1975. Earthquake-induced pressures on a rigid wall structure. Bulletin of New Zealand National Earthquake Engineering, 8, 175-186

Wu, G. ve Finn, W. L., 1999. Seismic lateral pressures for design of rigid walls. Canadian Geotechnical Journal, 36(3), 509-522

Younan, A. H. ve Veletsos, A. S., 2000. Dynamic response of flexible retaining walls. Earthquake Engineering and Structural Dynamics, 29(12), 1815-1844 